\title{
WALKING FROM CELEX TO EUR-LEX
}

\author{
Pascale Berteloot
}

Abstract: The present paper delivers a broad overview of the evolution of the access to European legal acts and documents and legal documentation during the first decade of this century from the perspective of the former head of EUR-Lex. It particularly reminds of the integration of the historical CELEX database into a new database called EUR-Lex which we know to-day. It shortly mentions the challenges of enlargements, transparency and free access to legal documents and shows how the early availability of documents could be implemented.

\section{Table of contents}

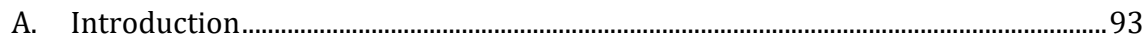

B. Taking stock of the Access to law at the beginning of the century ...........................94

C. The Integration of CELEX and EUR-Lex ………………………………………….....95

D. Early availability of documents ..................................................................................96

E. Enlargment.............................................................................................................97

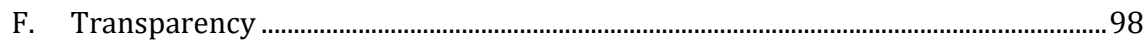

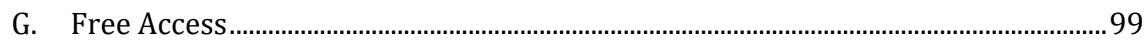

H. EUR-Lex and national law..............................................................................................99

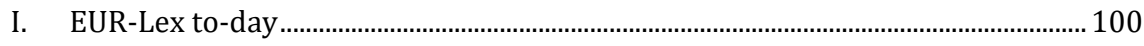

\section{A. INTRODUCTION}

When I first joined the Internationales Rechtsinformatik Symposion in Salzburg in 2001, the theme of the access to legal acts and documents and access to legal information was still central. There certainly was an interest in the way European institutions could cope with the challenges of the dissemination of elements related to a sui generis legal system 
expressed in parallel in a multiplicity of languages and aimed at lawyers and the general public with various national backgrounds.

At the time, some Member States already had developed systems for acceding legal documents, mostly legislative acts, more seldom with the integration of case-law. Other Member States were still about to develop systems for the access to law. Exchanging about experiences, heartening reaches and drawbacks, was a mutual enrichment. Above, Member States were eager to have a sensible integration between their national law and European law as only the conjunction of both resulted in the law applicable in their own country.

It was an interesting period with a lot of questioning which in the meantime seems deprecated, only because we could overcome. Besides those questions, political and factual reality was very demanding on the access to law: transparency, free access to information systems, successive enlargments to ten new Member States and later two more with new official languages, the introduction of more specific characters and the cyrilic alphabet, better regulation actions led by the Commission, electronic publishing of authenticated acts, loading of new documents as soon as they are released.

\section{B. TAKING STOCK OF THE ACCESS TO LAW AT THE BEGINNING OF THE CENTURY}

The feared bugs of the year 2000 transition had not appeared and the different existing systems for the access to law were safe. This marked the right time to integrate, to simplify and to extend for the benefit of the European citizen.

At the time, the Publications Office of the European Union (as called to-day) was in charge of the traditional CELEX which had been opened to the public in 1986; it had created EUR-Lex for acceding the Official Journal; Prelex, a system to follow the progress of legislative procedures was managed by the Secretariat General of the Commisison; Legislative Summaries, a tool aimed at a more simple and direct access to legislative acts was managed by the then General Directorate for Communication of the Commission. There was an urgent need of systematisation and integration in order to have a single point of access and deliver a better overview to the citizen. Reducing costs 
by aiming at a more logical and consistent management of legal databases was crucial as well.

The Publications Office was in no way taking decisions without consulations and discussions with stakeholders. Internally, an interinstitutional task-force, where every single institution was represented and could express its priorities, had delivered a report aiming at putting the Office in charge in spring 1999. An interinstitutional working party then followed the implementation. Both groups were reporting to the Mangement Committee of the Publications Office, a structure where every institution was represented at the level of their Secretary General. The link with Member States was given by the Council Working Group on Legal Data Processing (which in the meantime has two formations: e-Law and e-Justice, a new branding which also testifies of the evolution in the field of legal data processing). This Working Party was created at a very early stage of the development of CELEX within the Legal Service of the Commision, in 1974.

The main and first task was to integrate CELEX and EUR-Lex. The very beginnings of CELEX date back to the middle of the sixties of last century within the Legal Service of the Commission, when after the entry into force of the Treaty of Rome more legal acts were adopted and the human brain could not keep track anymore without a suitable tool. CELEX had been set up as a documentation service, each act entering the database being analysed and coming with a complete set of metadata. These metadata make the actual richness of the system as they allowed for a high variety of search criteria and delivered the legal information and still do. EUR-Lex on the contrary was born in 1998 within the Publications Office which main task is to publish the Official Journal every single day in all official languages. EUR-Lex was the electronic support system to deliver the electronic version of the Official Journal (OJ). The access to the documents in each of the issues of the $\mathrm{OJ}$ was offered through lists, i.e. a pure browsing access. It became obvious that both systems had to be integrated and that the unified tool was to give access to legal documentation as well as to the daily editions of the OJ.

\section{THE INTEGRATION OF CELEX AND EUR-LEX}

The first steps included developing a prototype with a new technical architecture, which would have to be agreed by stakeholders, i.e. the institutions as well as Member States. 
This phase began in July 2003. After having been developed, the new architecture was ready to take over the document collections in CELEX and allowed for the daily upload of the OJ editions. Simultaneously new search and browsing interfaces had to be developed.

The new system was made available to the public in late 2004, which means that the whole operation took about 18 months. It has however to be added that from late 2004 to the end of 2005 a lot of improvements as well as fine tuning were still necessary and were carried out.

After some hesitation, the new system which emanated from CELEX and EUR-Lex was called EUR-Lex. The naming appeared to be more suitable: CELEX seemed to be linked to a more sophisticated tool meant for professionals, while old-EUR-Lex with its browsing facilities had wanted to appear more accessible to the citizen. The new EUR-Lex system offered browsing, simple search criteria as well as more complex searching functionalities. It was essential to show that the citizen had been at the centre of concerns.

\section{EARLY AVAILABILITY OF DOCUMENTS}

One issue institutions as well as Member States wanted to see resolved in new EUR-Lex was the early availability of documents. Due to the thorough analysis of each document, it always took additional four to five days until a document appeared in CELEX after having been released. Especially the Court of Justice (CJ), which had changed its internal working procedures since 1994 to be able to release its judgments in parallel in all official languages instead of beginning translating them once given, insisted on early availability in EUR-Lex as well, even if they were also be made available on the CJ website.

Specific processing modes were put in place and thanks to well structured documents which allowed for the automatic retrieval of part of the metadata, the Court judgements were made available about one hour after their release and could be consulted by browsing or by searching on the basis of the criteria corresponding to the automated metadata (i.e. title, certain dates - of adoption, publication -, type of document). 
As for the Official Journal, it was clear that it had to be made available in the early morning of the day of its publication - or about an hour after publication if issues were published later during the day. The procedures were in place as from February 2004, to make sure new EUR-Lex would be able to cope with all the languages as from the day of the enlargement to ten new Member States. The basis for the binding electronic publication of the $\mathrm{OJ}$ as from the $1^{\text {st }}$ of July 2013 were thus laid down.

\section{E. ENLARGMENT}

While developing the new dissemination system and its infracture, enlargement to ten new Member States introducing nine new official languages took place: on the $1^{\text {st }}$ of May 2004, the OJ issues had to be uploaded in the new language editions as well. Besides, the acquis communautaire would normally as well have been published in order for European law to enter into force in the new Member States.

However, the translation of the acquis was cumbersome and none of the new Member States had delivered the entire volume of acts in its own language. When negociations for accession begin and during the whole time stretch of negociations, the exact content of the acquis, i.e. the legislation in force, has to be assessed and accordingly updated. For this task, EUR-Lex shows its role as a reference. As early as 1972, while CELEX was still managed by the Legal Service of the Commission, the need to have a clear view of all legislative acts in force, led to the conceptual design of a structured Directory of Legislation in Force, later made available in all official languages and monthly updated. This directory, based on the metada in EUR-Lex, delivers the content of the legislation in force which has to be made available in a new language to enter into force towards citizens of a new Member States. In this regard, it has to be updated a last time on the eve of accession.

Acceding Member States are responsible for the translation of all acts in force; translations are then revised by the Legal Services of the European Parliament, the Council and the Commission who share the task, before being published in a special edition of the OJ. When Denmark, Ireland and the United Kingdom joined the then European Communities as from the $1^{\text {st }}$ of January 1973, the acquis was still limited 
and could be published as a whole in time. The same applied when Greece joined and even for Portugal and Spain. Delays were already inevitable in 1995 when Finland and Sweden joined (no translation was needed for Austria). It was even worse for the next enlargments. However, EUR-Lex had to be in a position to make the OJ available in the new languages as from the day of accession, to proceed all new acts available in the new languages and to integrate gradually the acquis in the new languages in its databases.

\section{F. TRANSPARENCY}

An important legal act which dictated the evolution of CELEX and EUR-Lex was the adoption of Regulation EC 1049/2001 on public access to documents. This regulation states that the citizen is entitled to access documents of the public sector. Formally the regulation is addressed to Member States, but the European institutions declared they would also act in conformity with the requirements of the regulation. The main consequence of it was drawn by the European Parliament which insisted on the availability of all documents and steps of the legislative procedure. This lead to the stage by stage integration of Prelex into new EUR-Lex.

Basically, Prelex as managed by the Commission was giving a timeline of the legislative procedure and linked - wherever they were - to the various documents of the three institutions of the so-called legislative triangle (the Commission for the initiative, the European Parliament and the Council for the adoption). For the Publications Office, the task required to make sure to receive all documents linked to a legislative procedure to integrate them into the database, to receive full information on ongoing legislative procedures and to develop the appropriate tool showing their progress.

Nowadays, these documents - the only European ones which caused a problem for integration in the database, because institutions would not automatically send them over - are well managed by all parts and EUR-Lex allows for a quick overview of the stage of ongoing legislative procedures. 


\section{G. FREE ACCESS}

The requirements of transparency were accompanied by the request to make new EURLex freely available. CELEX had been a paying database. It was thought that mostly professionals were using it and that it was logical that the service offered could not be free.

However, this analysis was not true anymore. The whole context had changed. Legal databases were appearing in all Member States, they became a normal tool for more citizens; citizens showed an interest in legal documents. Above, transparency required that the citizen could freely access documents. Europe had also experienced a lack of confidence of citizens, particularly due to the difficulty to access documents and information.

The main problem was a budgetary one. CELEX was living on the collected fees. If it had to become freely available, its budget had to be secured. The European Parliament adopted a resolution by the end of 2002, asking for a specific budget which would allow the access to legal databases to be free of charge. By the midst of 2003, it became clear that the budgetary authorities would grant a specific budget and as from the $1^{\text {st }}$ of January 2004, the access to legal acts and documents and to legal information became free of charge.

\section{H. EUR-LEX AND NATIONAL LAW}

The narrow entanglement between European and national law - as well as the entanglement of industries, businesses and even citizens of various Member States - means that the authorities in Member States as well as their citizens are not only interested in European law but also in the law of their neighbours. This has lead to the request to make national measures implementing European law (directives) available in EUR-Lex and to a broader request to access national law. The request is in line with new ways of handling legislation in Member States, which are conscious of the similarity of problems they have to face, engage in more studies of comparative law and have gained an interest in the way other Member States legislate on a given topic. 
The availability of information on national measures implementing or transposing European law was planned as from the early beginnings of CELEX. Member States have to notify the Commission of the measures adopted to implement directives and the information could easily be passed to the database management. These procedures had to be renewed and to-day information is properly transmitted. Member States are however also interested in the very text of the measures. From far, this seems very easy when you think Member States have well developed legal databases to which it is easy to link which is not always the case. Member States in the meantime often notify the adoption of the measure adding a copy of the actual text which is then downloaded and made available in EUR-Lex. A link to machine translation is also available and allows for a translation which at least gives an idea of the content.

It is worth mentioning that Member States have engaged in a project to ease the access to national legislation via a standardised format allowing for exchange and reuse across borders: the ELI (European Legislative Identifier) project. Some Member States are already very far in its implementation while others just began.

There is also an interest in national case-law and some case-law is now available via EUR-Lex. From the beginnings of CELEX it has been planned to give access to case-law related to European law, especially to national judgments following a preliminary ruling by the Court of Justice. The project is still under way. Via a working group which reported to the Council Working Party on Legal Data Processing, the Council adopted a resolution to implement a standardised format: the ECLI (the European Case Law Identifier), which already exists at EU-level and in some Member States.

\section{EUR-LEX TO-DAY}

Technological progress made it possible to rethink the whole of the backoffice management of the database, to ease downloading and reuse of data and still try to have more convincing interfaces. There is also a steady enrichment of the collections.

It is quite amazing to notice that the strict documentary definition of the identifier of each document, the CELEX number adopted in the very beginnings of the early database and which already gives information on the type of act, the year of adoption and 
the number of the document itself is still very much in use to-day and still corresponds to the needs of users.

If a suggestion can be made as to further ease the access and intelligibility of EU-law: it would be worth to explore the benefits of modelling and introduce more graphic representation of the content and the search results.

Finally, a wish: long life to EUR-Lex and beneficial further improvements!1

1 For more information see the database itself which includes some explanatory notices, as well as - for more internal information related to the work on CELEX and EUR-Lex at the beginning of the century: PubliCATIONS OfFicE, 25 Years Of European Law Online (2 volumes), 2007, Luxembourg. 
